\title{
Ontogenetic and seasonal changes in the diets of the glowbelly Acropoma japonicum Gunther, 1859 in the south-eastern waters of Korea
}

\author{
JOO MYUN PARK AND SUNG-HOI HUH* \\ Department of Marine Bioscience, Gangneung-Wonju National University, Ganeneung - 25457, Korea \\ *Department of Oceanography, Pukyong National University, Busan - 48280, Korea \\ e-mail:joomyun@gmail.com
}

\begin{abstract}
ABSTACT
The dietary patterns of the glowbelly Acropoma japonicum Gunther, 1859 were studied based on 180 specimens collected during January to December 2006 off the south-eastern coast of Korea. The standard length (SL) of the specimens ranged from 3.0 to $10.3 \mathrm{~cm}$. A. japonicum was found to be a benthopelagic predator that primarily consumed copepods and carid shrimps, but also preyed moderately on teleosts and euphausiids. The dietary composition of $A$. japonicum differed between length classes, with copepods and carid shrimps being dominant in the diet of small and large length class, respectively. The diets also were different among seasons, with the difference particularly being evident between warm (summer and autumn) and cold (winter and spring) seasons. Permutational multivariate analysis of variance (PERMANOVA) and analysis of similarities (ANOSIM) revealed significant dietary differences by size and season. These differences in the diets were related to first maturity in female and seasonal changes in water temperature.
\end{abstract}

Keywords: Caridea, Copepoda, Glowbelly, South-eastern Korea, Stomach contents

\section{Introduction}

The glowbelly, Acropoma japonicum Gunther, 1859, is a benthopelagic fish (Perciformes: Acropomatidae) that is widely distributed throughout tropical and temperate waters inhabiting the continental shelf from the West Pacific to the Indian Ocean (Nakabo, 2002). Fishes of the family Acropomatidae including A. japonicum, constitute approximately 32 species in 7 genera distributed worldwide (Froese and Pauly, 2017), while only 5 species in 3 genera occur in Korean waters (Kim et al., 2005). A. japonicum is smaller $(\mathrm{TL}=15 \mathrm{~cm})$ than other members of the same family found in Korea (Kim et al., 2005).

Several of the larger fishes such as Doederleinia berycoides grow large enough to be marketed in Korea (NFRDI, 2004). A. japonicum however, forms a major component of the trawl bycatch in Korean waters (Park, 2010). In south-western Japan on the other hand, it is commercially used for manufacturing fried fish cake (Okuda et al., 2005). A. japonicum is regarded as an ecologically important species because of its high abundance and prominence in the diets of other fishes in south-eastern Korean marine ecosystems (Park, 2010; Park et al., 2014; Park and Huh, 2017).

Despite the high abundance of $A$. japonicum in the study area, little is known about its ecology or biology.
Just a few studies have described its life history (Okuda et al., 2005), reproduction (Baeck et al., 2012) and morphological features (Javadzadeh et al., 2012) and a single paper described the diet and isotopic signatures of A. japonicum in the Uwa Sea, Japan (Hamaoka et al., 2010). There is, no targeted study on how feeding may change with increasing body size and season in south-eastern Korea. Based on its TROPH value (i.e., secondary and/or tertiary consumers), A. japonicum often occupies the intermediate trophic level (Froese and Pauly, 2017). Hamaoka et al. (2010) also reported that A. japonicum plays an important role in bentho-pelagic coupling food webs, because they feed on a variety of prey organisms from zooplankton to benthic fishes and shrimps. Thus, the information on its diet is essential to understand the trophic relationships within marine ecosystems and knowledge of the feeding ecology of marine predators within the food web will aid in identifying the functional roles of these fishes within marine ecosystems (Wootton, 1990; Brodeur and Pearcy, 1992).

This study attempted to quantify the diet of A. japonicum which is abundant in south-eastern sea of Korea. The specific aims of this study were to determine the dietary composition of $A$.japonicum and to identify any size-related and seasonal changes in dietary composition. 


\section{Materials and methods}

\section{Study area and sampling}

Fishing grounds located off the south-eastern waters of Korea $\left(35^{\circ} 17^{\prime} \mathrm{N}, 129^{\circ} 18^{\prime} \mathrm{E}\right.$; Fig. 1) exhibit environmental and geographical characteristics that distinguish them from the coastal marine ecosystems of the eastern and southern Korean seas (Park, 1978). The region enjoys favourable environmental conditions in terms of water temperature, salinity and bottom sediments (clay-rich mud and silt mud) and is home to many commercially important benthopelagic fishes such as blackthroat seaperch Doederleinia berycoides, Japanese anchovy Engraulis japonicus, Tanaka's snailfish Liparis tanakae, yellow goosefish Lophius litulon and John dory Zeus faber (NFRDI, 2004).

Sampling was performed at monthly intervals during the period from January to December 2006. Fish were collected at depths of 30-60 m using a small bottom trawl with $30 \mathrm{~mm}$ mesh cod end and $20 \mathrm{~m}$ headline length. Trawling was carried out during daylight (between 06: 00 and 12:00 hrs) at neap tides. Immediately after capture, fish were packed in ice and taken to the laboratory. Standard length (SL) and wet weight were measured to the nearest $\mathrm{mm}$ and nearest $\mathrm{g}$, respectively. Stomachs dissected out, preserved in 5\% formalin for $24 \mathrm{~h}$ and transferred to $70 \%$ isopropanol.

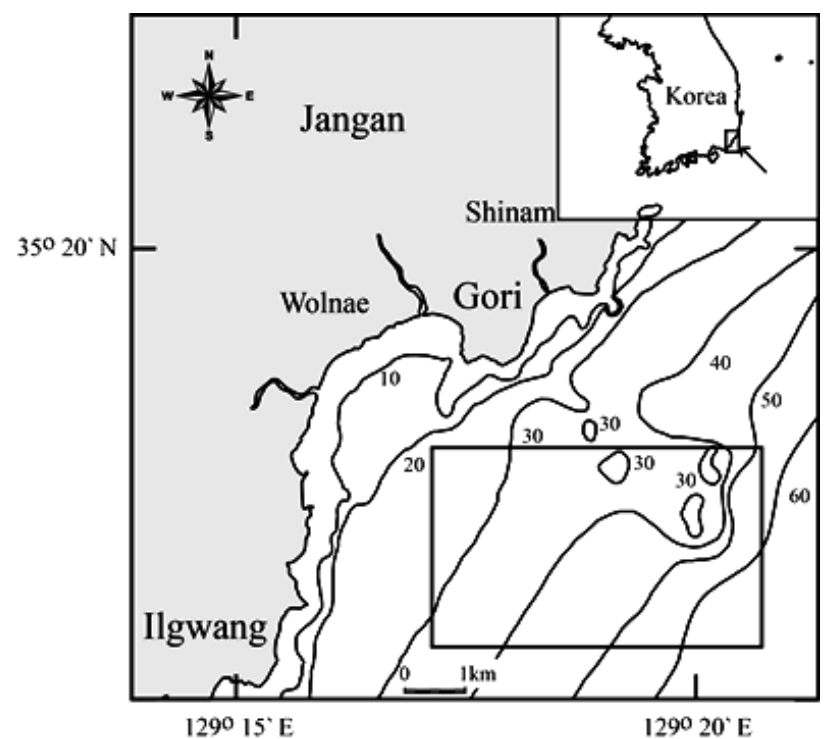

Fig. 1. Location of the study area off the south-eastern coast of Korea. Samples of Acropoma japonicum were collected at random locations within the boxed area using small bottom trawl

\section{Stomach content analysis}

The prey items were identified as accurately as possible to the species/genus level. The unidentifiable prey items and partly digested material were categorised at higher taxonomic levels (family or order levels). The prevalence of each prey item was quantified with the aid of a dissecting microscope. The numbers and dry weights of each prey item were recorded after drying for $24 \mathrm{~h}$ in an electric oven at $80^{\circ} \mathrm{C}$.

Cumulative prey curves were constructed for each species to determine whether a sufficient number of stomachs was analysed to describe the diet (Ferry and Cailliet, 1996). To achieve this, the order of dietary data was randomised 100 times and the cumulative number of new prey taxa was recounted for each randomisation. The mean number of prey taxa per stomach $( \pm \mathrm{SD})$ was plotted against the number of stomachs analysed, with the asymptote of the curve indicating that an adequate number of stomachs were studied.

To infer whether there were any size-related and seasonal variation in the dietary composition, samples were divided into two length classes and four seasons. For size-related analysis, samples were divided into two groups (small and large length classes) based on their size at maturity, i.e., $6.0 \mathrm{~cm}$ SL (Baeck et al., 2012). Thus, for the analyses, the length classes were defined as small (3.0-5.9 $\mathrm{cm} \mathrm{SL}, \mathrm{n}=104)$ and large $(6.0-10.3 \mathrm{~cm} \mathrm{SL}$, $\mathrm{n}=76$ ); the seasons as spring (March-May, $\mathrm{n}=70$ ), summer (June-August, $\mathrm{n}=12$ ), autumn (September-November, $\mathrm{n}=58$ ) and winter (December-February, $\mathrm{n}=40$ ).

Diet was quantified by frequency of occurrence $(\% \mathrm{~F})$, numerical percentage $(\% \mathrm{~N})$ and weight percentage $(\% \mathrm{~W})$ and the index of relative importance (IRI) (Pinkas et al., 1971; Hyslop, 1980). IRI was expressed as percentage (\%IRI).

\section{Statistical analysis}

Difference in mean SL between cold (winter and spring) and warm (summer and autumn) season was assessed using one-way analysis of variance (ANOVA) with season as fixed effect.

To examine the relative extents to which the dietary compositions of fish were influenced by size and season, stomachs of each of the species were randomly sorted into groups of three to five within each length class in each season (depending on the sample size) and the mean percentage weight data for each of the prey taxa were determined for each of the resultant groups. The weight data were square root transformed to avoid any tendency for the main dietary components to be excessively dominant and Bray-Curtis similarity matrices were constructed (Platell and Potter, 2001). The effects of 
size and season as well as their interactions were tested using two-way permutational multivariate analysis of variance (PERMANOVA). Two-way crossed analysis of similarities (ANOSIM) were then used to determine the relative importance of length class and season based on the same factors as used in the PERMANOVA (see above). In cases where ANOSIM detected a significant difference, pair-wise ANOSIM comparisons were then used to determine which comparisons between seasonal groups showed significant differences (Clarke et al., 2014).

To obtain a graphical ordination of the samples, principal coordinate analysis (PCO) of unconstrained ordinations based on Bray-Curtis similarity was used, employing the mean weight percentage of prey taxa for length classes and seasons. The relative contribution of prey taxa to the differences between length classes and among seasons was assessed using the correlation coefficient. The correlation of prey taxa $>0.4$ was used as an arbitrary limit of a strong relationship between the dietary composition of each group and prey taxa on the principal coordinate axes.

ANOVA was performed using SYSTAT software (Systat version 18. SPSS Inc., USA). Multivariate analyses were performed using the routines in the PRIMER v7 multivariate statistics package (www.primer-e.com) and the PERMANOVA+ add-on module (Anderson et al., 2008; Clarke and Gorley, 2015). For all tests, the significance level was set at $\mathrm{p}=0.05$.

\section{Results}

\section{General stomach contents}

Among 180 specimens of A. japonicum, caught during study period, no fishes were collected in June and July (Fig. 2). During colder season, the samples mainly consisted of small individuals, while larger adults were main components between August and October samples (Fig. 2). ANOVA results revealed that mean size $( \pm \mathrm{SD})$ of $A$. japonicum in warm season $(6.7 \pm 1.9 \mathrm{~cm})$ was significantly higher than that of cold season $(4.7 \pm 1.1 \mathrm{~cm})$ (ANOVA, $\mathrm{p}<0.05$ ).

In the 180 stomachs analysed, 34 (18.9\%) were empty. A cumulative prey curve for overall diet (number of prey taxa found) reached asymptote (Fig. 3). Thus, the sample sizes were enough to allow us to adequately describe the diet of $A$. japonicum in the study area.

A total of 9 prey taxa were found in the 146 stomachs (Table 1). Copepods were the most common prey item, recording $39.7 \%$ occurrence, $71.8 \%$ by number, $14.6 \%$ by dry weight and $50.8 \%$ IRI. At least 7 copepod genera were identified. Calanus and Acartia were the principal copepod prey items. Carid shrimps were the second largest dietary component, totalling $45.2 \%$ occurrence, $12.9 \%$ by number, $39.6 \%$ by dry weight and $35.2 \%$ IRI. The principal shrimp prey species found was Leptochela sydniensis. Teleosts and euphausiids accounted for 6.8 and $6 \%$ IRI, respectively and all of the remaining prey taxa constituted less than $1 \%$ IRI.

\section{Variation in stomach contents by size and season}

When the dietary data were examined by length classes, the small length class of $A$. japonicum fed mainly on copepods, euphausiids and carid shrimps, the first two of which declined in importance as the body size of this predator increased (Fig. 4a). In contrast, contribution of carid shrimps and teleosts became greater with increasing body size of $A$. japonicum (Fig. 4a). When the dietary data were examined by season, seasonal differences in dietary compositions were found in the diets of A. japonicum (Fig. 4b). Dietary compositions of $A$. japonicum in winter and spring comprised mainly copepods and carid shrimps (Fig. 4b). During summer, however, carids (40.3\%) were the most important dietary component, followed by crabs (13.4\%) and teleosts (11.6\%). Carid shrimps and teleosts were important in autumn diets, collectively contributing $70.5 \%$ to the overall dietary volume (Fig. $4 \mathrm{~b}$ ).

PERMANOVA tests revealed that the dietary composition significantly differed between length classes (pseudo- $\mathrm{F}=8.396, \mathrm{df}=1, \mathrm{p}=0.001$ ) and among seasons (pseudo- $\mathrm{F}=2.914, \mathrm{df}=3, \mathrm{p}=0.025$ ). There was also a significant interaction between factors of size and season (pseudo-F=3.207, $\mathrm{df}=3, \mathrm{p}=0.005$ ). The results of twoway crossed ANOSIM tests also showed that the dietary compositions of $A$. japonicum were significantly different with length class (global- $\mathrm{R}=0.884, \mathrm{p}=0.001$ ) and season (global-R=0.548, $\mathrm{p}=0.002$ ). Pairwise ANOSIM tests revealed that pairwise seasonal comparisons between cold season (winter and spring) and warm season (summer and autumn) were significant, but not significant between summer and autumn (global-R=0.291, $\mathrm{p}=0.163$ ) and between winter and spring (global- $\mathrm{R}=0.021, \mathrm{p}=0.394$ ).

The unconstrained ordination plot using the first two principal coordinates axis show a clear separation of samples along the $1^{\text {st }}$ and $2^{\text {nd }}$ axes, which explained 48.4 and $30.1 \%$ of the variation within samples, respectively (Fig. 5). Samples of large length class were distributed on the upper right of the plot, while samples of small length class spread out on the plot, with the exception of upper right region. In PCO plot, copepods, amphipods and euphausiids were driving the differences on the small length class, whereas carid shrimps and teleosts were characterised by the large length class (Fig. 5). In terms of season, the points of winter and spring showed a clear 


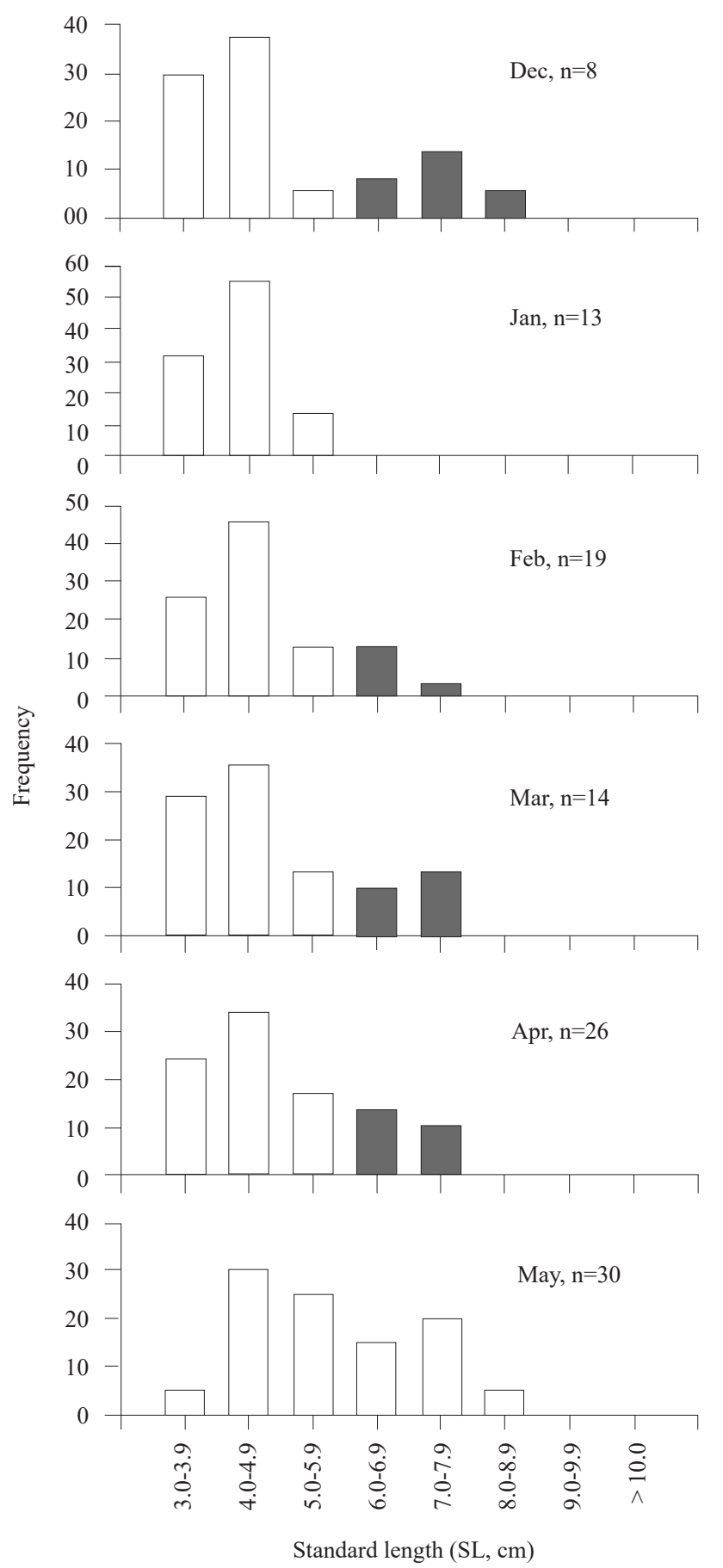

(a)
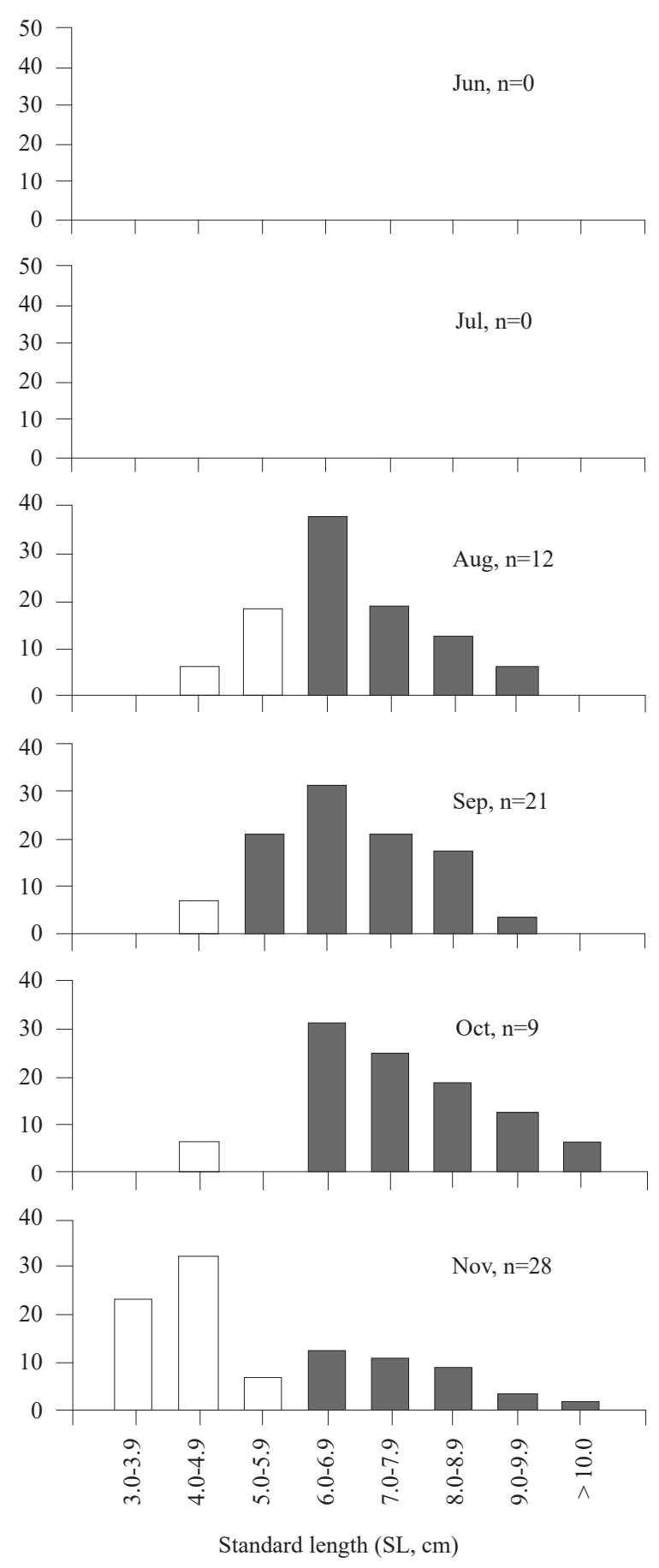

(b)

Fig. 2. Monthly variations in size frequency of Acropoma japonicum during (a) cold and (b) warm seasons. White bars $=$ small length class, Grey bars $=$ large length class

separation from those of summer and autumn along the first axis (Fig. 5). Copepods and chaetognaths highly correlated with winter and spring samples, while various prey taxa showed positive correlations with summer and autumn (Fig. 5).

\section{Discussion}

Based on the \%IRI values, the greatest contributors in the diets of $A$. japonicum were copepods and carid shrimps, with the majority being pelagic or benthopelagic foods thus suggesting foraging in water column. The 
Table 1. Percentage frequency of occurrence $(\% \mathrm{~F})$, number $(\% \mathrm{~N})$, dry weight $(\% \mathrm{~W})$, and index of relative importance $(\% \mathrm{IRI})$ of prey items in the diets of Acropoma japonicum inhabiting south-eastern waters of Korea

\begin{tabular}{|c|c|c|c|c|c|}
\hline Taxa & Prey items & $\% \mathrm{~F}$ & $\% \mathrm{~N}$ & $\% \mathrm{~W}$ & $\%$ IRI \\
\hline \multicolumn{6}{|l|}{ Crustacea } \\
\hline \multirow[t]{8}{*}{ Copepoda $^{*}$} & Total & 39.7 & 71.8 & 14.6 & 50.8 \\
\hline & Acartia & 13.7 & 22.5 & 4.4 & \\
\hline & Calanus & 30.1 & 46.6 & 9.1 & \\
\hline & Centropages & 1.4 & 0.2 & 0.1 & \\
\hline & Corycaeus & 1.4 & 0.4 & 0.1 & \\
\hline & Euchaeta & 2.7 & 0.4 & 0.2 & \\
\hline & Nudinula & 1.4 & 0.4 & 0.2 & \\
\hline & Paracalanus & 2.7 & 1.4 & 0.5 & \\
\hline Ostracoda $^{*}$ & Unidentified & 1.4 & 0.2 & 0.1 & $<0.1$ \\
\hline Mysidacea* & Unidentified & 2.7 & 0.4 & 0.8 & $<0.1$ \\
\hline Euphausiacea* $^{*}$ & Unidentified & 20.5 & 7.2 & 12.5 & 6.0 \\
\hline \multirow[t]{3}{*}{ Amphipoda* } & Total & 12.3 & 3.5 & 2.1 & 1.0 \\
\hline & Hyperidae & 9.6 & 2.3 & 1.7 & \\
\hline & Gammeridae & 2.7 & 1.2 & 0.4 & \\
\hline \multicolumn{6}{|l|}{ Decapoda } \\
\hline \multirow[t]{4}{*}{ Caridea $^{*}$} & Total & 45.2 & 12.9 & 39.6 & 35.2 \\
\hline & Eualus spathulirostris & 1.4 & 0.2 & 2.8 & \\
\hline & Leptochela sydniensis & 27.4 & 9.8 & 25.9 & \\
\hline & Unidentified & 20.5 & 2.9 & 11.0 & \\
\hline Brachyura* $^{*}$ & Megalopa larvae & 1.4 & 0.4 & 0.9 & $<0.1$ \\
\hline Chaetognatha* $^{*}$ & Sagitta spp. & 4.1 & 0.8 & 1.6 & 0.1 \\
\hline \multirow[t]{3}{*}{ Teleostei $^{*}$} & Total & 15.1 & 2.7 & 27.6 & 6.8 \\
\hline & Myctophidae & 11.0 & 2.2 & 25.0 & \\
\hline & Unidentified & 4.1 & 0.6 & 2.6 & \\
\hline
\end{tabular}

*Indicates prey taxa for multivariate analyses

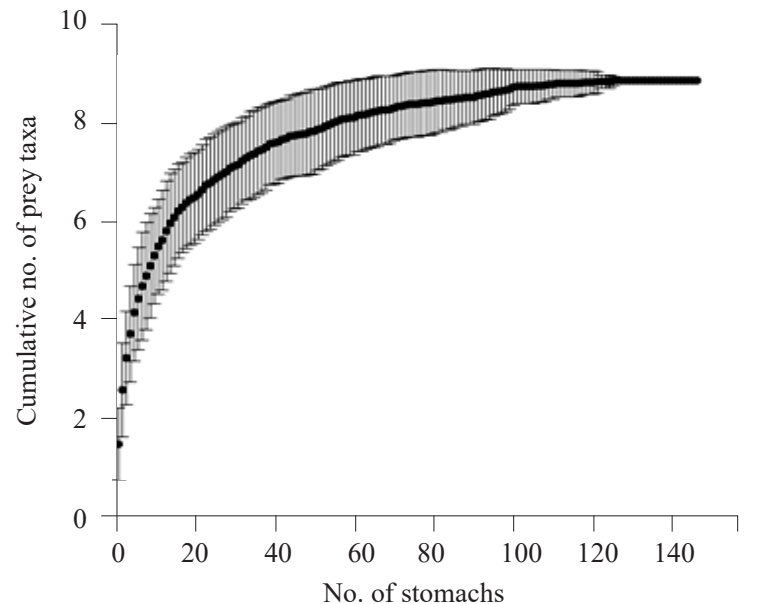

Fig. 3. Cumulative prey curves (prey taxa per stomach; \pm SD) for Acropoma japonicum from the south-eastern waters of Korea

importance of these prey items was also found in the diets of A. japonicum in Japanese waters (Hamaoka et al., 2010). However, there was also region-specific differences in food resources between Korean and Japanese waters. In the Uwa Sea of Japan, teleosts (mostly gobies) formed major

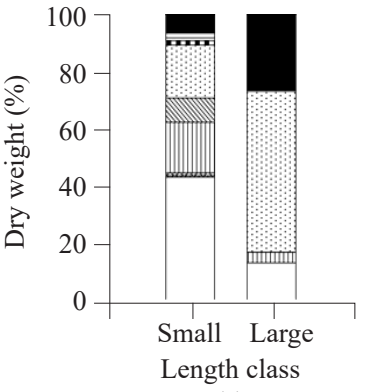

(a)

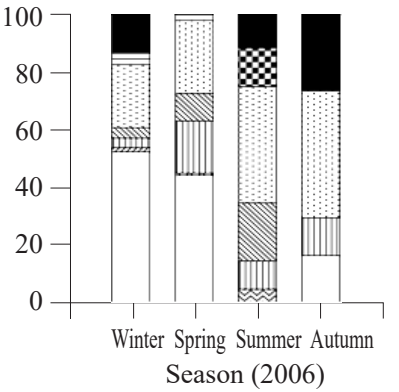

(b) $\square$ Copepoda, m шس Euphausiacea, Amphipoda, … Caridea, $\mathbf{m}$ Brachyura, Chaetognatha, Teleostei

Fig. 4. Ontogenetic (a) and seasonal (b) variations in dietary compositions of Acropoma japonicum in the south-eastern waters of Korea

components in the diets of A. japonicum, followed by penaeid shrimps, while carid shrimps and copepods were more abundant in the diets of the species in Korean waters. Generally, fish target the most abundant available prey, which is indicative of the benthopelagic faunistic composition. 


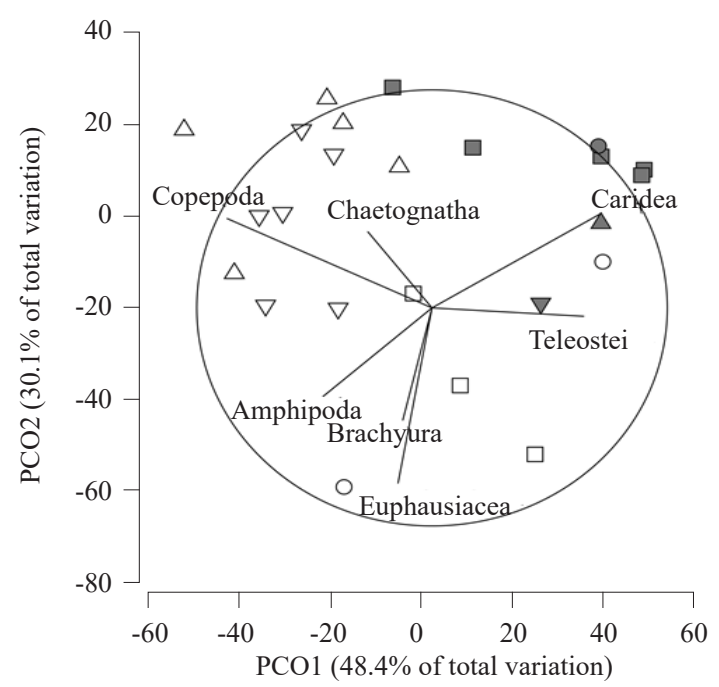

Fig. 5. Principal coordinate (PCO) analysis using an agglomerative ordination method based on dietary compositions across different length classes (open symbol $=$ small length class, grey symbol $=$ large length class) and seasons (triangle $=$ winter, inverted triangle $=$ spring, square $=$ summer, circle $=$ autumn) in the southeastern waters of Korea. The vector represents Pearson correlation and the circle shows a correlation of 1

Although a high diversity of decapods was evident in our study area (Huh et al., 2010), A. japonicum usually consumed pasiphaeid shrimps i.e., Leptochela sydniensis. These prey items were frequently consumed by co-occurring pelagic fishes including Coilia nasus (Baeck et al., 2011), Clupea pallasii pallasii and juvenile Trichiurus lepturus (Choo, 2007) and also other fishes elsewhere such as Chelidonichthys spinosus from the Jeju Island (Kim et al., 2011) and the sardine Sardinops sagax and barracouta Thyrsites atun from southern Australia (Bulman et al., 2011). Pasiphaeid shrimps are a family of mesopelagic decapods from shelf and offshore environments (Poore, 2004) and thus predation on pasiphaeid shrimps indicate pelagic feeding behaviours of predatory fishes. However, many sympatric benthic fishes in the study area such as Amblychaeturichthys gobies (Huh et al., 2016) and fivespot flounder (Pseudorhombus pentophthalmus; Park and Huh, 2017), fed on crangonid shrimps which were the most dominant benthic shrimps in the study area (Huh et al., 2010). Although fish target the most abundant locally available prey and such behaviour may be influenced by the catch success rate and/or the probability of encountering prey (Persson and Diehl, 1990), A. japonicum specialised on pasiphaeid shrimps. This feeding strategy of $A$. japonicum likely reduces potential competition for available prey resources among co-occurring fish species in the study area.
Both PERMANOVA and ANOSIM revealed significant size-related difference in the diets of A. japonicum. Ontogenetic dietary change of $A$. japonicum mainly included shift from copepods to carid shrimps. Such an increase in the contribution of carid shrimps and teleosts may be partly explained by an increase in actual mouth size as A. japonicum grew (data not shown), thus increasing the capture efficiency of larger and more active prey (Scharf et al., 2000). Among fishes of the Family Acropomatidae, the relatively large-sized Doederleinia berycoides also showed distinct ontogenetic dietary changes from crustaceans to fishes, as body size increased (Huh et al., 2011). Size-related changes from small crustaceans (e.g. copepods) to larger shrimps and/ or euphausiids are a general trend in the diets of small pelagic and/or benthopelagic fishes (Kock et al., 2000; Choo, 2007; Baeck et al., 2011). Such ontogenetic dietary changes may be related to maximize energy acquisition (Gerking, 1994), i.e. larger fish prefer bigger prey because they contain more energy and exploit their increased mobility to catch such prey (Stoner and Livingston, 1984).

Seasonal changes in feeding habits are associated with changes in food availability caused by environmental factors and physiological variation (Wootton, 1990). Although A. japonicum principally consumed copepods and carid shrimps, marked difference was observed in the diets among seasons. These differences were particularly evident between cold $\left(13.6-14.7^{\circ} \mathrm{C}\right)$ and warm season (16.0-26.5 ${ }^{\circ} \mathrm{C}$; Park, 2010), with copepods being more in the former season, while carid shrimps more in the latter season. This could be probably due to differences in size distributions between seasons, because PERMANOVA showed that diet compositions of A. japonicum significantly interacted with size and season. Since mean size in cold season was significantly lower than that of warm season, the seasonal differences in diets strongly attributed the different size composition between cold and warm seasons. However, due to the lack of information on seasonal abundance of prey items in this study, the reasons behind the abundance of copepods and carid shrimps in the diet of A. japonicum during cold and warm season remain unclear.

In conclusion, this study offers important insights into the dietary habits of $A$. japonicum that are abundant in the south-eastern waters of Korea. Stomach contents indicated that they consumed mainly pelagic (e.g. copepods and euphausiids) and benthopelagic (e.g. carid shrimps) crustaceans, independent of size or season. Copepods were consumed by smaller individuals and during cold season, while carid shrimps were abundant in the diets of larger fishes and during warm season. Nonetheless, a lack of samples covering all possible size 
ranges imposed limitations on describing absolute diet of the species throughout its entire life history. Additional studies on the trophic ecology of $A$. japonicum are essential to understand prey-predator relationships in benthic ecosystems of the eastern Korean Sea. Results from this study would contribute to the understanding of A. japonicum dietary habits, and serve as an important baseline for future food web analyses for various fishes in the region.

\section{Acknowledgments}

We are indebted to Dr. Ki Moon Nam and Mr. Ja Heok $\mathrm{Gu}$ for their assistance in sample collection. We also would like to thank Laith Jawad for reading the manuscript and for his valuable suggestions. Field surveys were conducted under approval of "Research \& Training Fishery" in Ministry of Ocean and Fisheries, Korea. This research was supported by National Institute of Fisheries Science (R2018049).

\section{References}

Anderson, M. J., Gorley, R. N. and Clarke, K. R. 2008. PERMANOVA+ for PRIMER: Guide to software and statistical methods. PRIMER-E, Plymouth Marine Laboratory, Plymouth.

Baeck, G. W., Huh, S. H. and Park, J. M. 2012. Reproductive ecology of the glowbelly, Acropoma japonicum (Perciformes: Acropomatidae) in the coastal waters off Gori, Korea. J. Korean Soc. Fish. Technol., 48(2): 118-127.

Baeck, G. W., Park, J. M., Choo, H. K. and Huh, S. H. 2011. Diet composition of Coilia nasus in the coastal waters off Gori, Korea. Korean J. Ichthyol., 23(2): 163-167.

Brodeur, R. D. and Pearcy, W. G. 1992. Effects of environmental variability on trophic interactions and food web structure in a pelagic upwelling ecosystem. Mar. Ecol. Prog. Ser., 84(2): 101-119.

Bulman, C. M., Condie, S. A., Neira, F. J., Goldsworthy, S. D. and Fulton, E. A. 2011. The trophodynamics of small pelagic fishes in the southern Australian ecosystem and the implications for ecosystem modelling of southern temperate fisheries. Final report for FRDC project 2008/023, CSIRO Marine and Atmospheric Research, Hobart, Australia, $101 \mathrm{pp}$.

Choo, H. G. 2007. Species composition and feeding ecology of fishes in the coastal waters off Kori, Korea. Ph. D Thesis, Pukyong National University, Busan, Korea, 126 pp.

Clarke, K. R., Gorley, R. N., Somerfield, P. J. and Warwick, R. M. 2014. Change in marine communities: an approach to statistical analysis and interpretation, $3^{\text {rd }}$ edn. PRIMER-E, Plymouth, UK.

Clarke, K. R. and Gorley, R. N. 2015. PRIMER v7: User Manual/ Tutorial, PRIMER-E, Plymouth, U. K.
Ferry, L. A. and Cailliet, G. M. 1996. Sample size and data analysis: are we characterising and comparing diet properly? In: MacKinlay, D. and Shearer, K. (Eds.), International congress on the biology of fishes, San Francisco, California, p. 71-80.

Froese, R. and Pauly, D. 2017. Fish Base 2017. World Wide Web electronic publication. www.fishbase.org (Accessed January 2017).

Gerking, S. D. 1994. Feeding ecology of fish. Academic Press, San Diego, USA, 416 pp.

Hamaoka, H., Okuda, N., Fukumoto, T., Miyasaka, H. and Omori, K. 2010. Seasonal dynamics of a coastal food web: stable isotope analysis of a higher consumer. Earth, life and isotopes. Kyoto University Press, Kyoto, p. 161-181.

Huh, S. H., Oh, H. S., Park, J. M. and Baeck, G. W. 2011. Feeding habits of the blackthroat seaperch Doederleinia berycoides in the Southern Sea of Korea. Korean J. Fish. Aquat. Sci., 44(3): 284-289.

Huh, S. H., Park, J. M., Jeong, D. S. and Baeck, G. W. 2010 Seasonal and interannual variation in species composition and abundance of decapod assemblages collected using pots in the coastal waters off Gori, Korea. Korean J. Fish. Aquat. Sci., 43(5): 293-297.

Huh, S. H., Park, J. M. and Baeck, G. W. 2016. Diet partitioning between co-occurring Amblychaeturichthys hexanema and Amblychaeturichthys sciistius in the South-eastern Korean waters. Korean J. Ichthyol., 28(2): 79-86.

Hyslop, E. J. 1980. Stomach contents analysis - a review of methods and their application. J. Fish Biol., 17(4): 411-429.

Javadzadeh, N., Vosoughi, G., Valinassab, T., Fatemi, M. R. and Abdoli, A. 2012. Morphological features of two mesopelagic fish (Acropoma japonicum and Synagrops adeni) from the Oman Sea, Iran. World Appl. Sci. J., 17(4): 494-496.

Kim, I. S., Choi, Y., Lee, C. L., Lee, Y. J., Kim, B. J. and Kim, J. H. 2005. Illustrated book of Korean fishes. Kyo-Hak Publishing, Seoul, Korea, 615 pp.

Kim, J. B., Kim, J. Y., Lee, D. W. and Choi, J. H. 2011. Feeding habits of bluefin searobin Chelidonichthys spinosus around Jeju Island. Korean J. Fish. Aquat. Sci., 44(4): 378-382.

Kock, M., Focken, U., Richter, H., Becker, K. and Santiago, C. B. 2000. Feeding ecology of silverperch, Terapon plumbeus Kner, and the impact of fish pens in Laguna de Bay, Philippines. J. Appl. Ichthyol., 16(6): 240-246.

Nakabo, T. 2002. Fishes of Japan with pictorial keys to the species. Tokai University Press, Tokyo, 1749 pp.

NFRDI 2004. Commercial fishes of the coastal and offshore waters in Korea. Hangel, Busan, Korea, 333 pp.

Okuda, N., Hamaoka, H. and Omori, K. 2005. Life history and ecology of the glowbelly Acropoma japonicum in the Uwa Sea, Japan. Fish. Sci., 71(5): 1042-1048. 
Park, C. G. 1978. Chemical oceanographic aspect of the cold water mass in offshore of the east coast of Korea. Korean J. Fish. Aquat. Sci., 11(2): 49-54.

Park, J. M. 2010. Species composition and reproductive ecology of fishes in the coastal waters off Gori, Korea. Ph. D Thesis. Pukyong National University, Busan, 236 pp.

Park, J. M. and Huh, S. H. 2017. Dietary habits and feeding strategy of the fivespot flounder, Pseudorhombus pentophthalmus in the south-eastern coast of Korea. Ichthyol. Res., 64(1): 93-103.

Park, J. M., Huh, S. H., Jeong, J. M. and Baeck, G. W. 2014. Diet composition and feeding strategy of yellow goosefish, Lophius litulon (Jordan, 1902), on the south-eastern coast of Korea. J. Appl. Ichthyol., 30(1): 151-155.

Persson, L. and Diehl, S. 1990. Mechanistic individual-based approaches in the population/community ecology of fish. Annales Zoologici Fennici. Finnish Zoological Publishing Board, Finnish Academy of Sciences, Societas Scientiarum Fennica, Societas Biologica Fennica Vanamo and Societas pro Fauna et Flora Fennica, p. 165-182.
Pinkas, L., Oliphant, M. S. and Iverson, I. L. K. 1971. Food habits of albacore, bluefin tuna and bonito in California waters. Fish. Bull., 152: 1-105.

Platell, M. E. and Potter, I. C. 2001. Partitioning of food resources amongst 18 abundant benthic carnivorous fish species in marine waters on the lower west coast of Australia. J. Exp. Mar. Biol. Ecol., 261(1): 31-54.

Poore, G. C. 2004. Marine decapod crustacea of southern Australia: A guide to identification. CSIRO Publishing, Collingwood, $574 \mathrm{pp}$.

Scharf, F. S., Juanes, F. and Rountree, R. A. 2000. Predator size-prey size relationships of marine fish predators: interspecific variation and effects of ontogeny and body size on trophic-niche breadth. Mar. Ecol. Prog. Ser., 208: 229-248.

Stoner, A. W. and Livingston, R. J. 1984. Ontogenetic patterns in diet and feeding morphology in sympatric sparid fishes from sea-grass meadow. Copeia, 1984: 174-178.

Wootton, R. J. 1990. Ecology of teleost fishes. Chapman and Hall, New York, 404 pp.

Date of Receipt $\quad$ : 12.02 .2017

Date of Acceptance : 22.12 .2017 